\title{
openheart Role of dietary histidine in the prevention of obesity and metabolic syndrome
}

\author{
James J DiNicolantonio, ${ }^{1}$ Mark F McCarty, ${ }^{2}$ James H OKeefe (D) ${ }^{1}$
}

To cite: DiNicolantonio JJ, McCarty MF, OKeefe JH. Role of dietary histidine in the prevention of obesity and metabolic syndrome. Open Heart 2018;5:e000676. doi:10.1136/ openhrt-2017-000676

Accepted 24 April 2018

Check for updates

${ }^{1}$ Department of Preventive Cardiology, Saint Lukes Mid America Heart Institute, Kansas City, Missouri, USA

${ }^{2}$ Catalytic Longevity, Encinitas, California, USA

\section{Correspondence to} Dr James J DiNicolantonio; jjdinicol@gmail.com

\section{HISTIDINE SUPPLEMENTATION AMELIORATES METABOLIC SYNDROME}

A recent Chinese supplementation study, in which obese middle-aged women diagnosed with metabolic syndrome received 12 weeks of supplemental histidine ( $2 \mathrm{~g}$, twice daily) or matching placebo, achieved remarkable findings. ${ }^{1}$ Insulin sensitivity improved significantly in the histidine-supplemented subjects, and this may have been partially attributable to loss of body fat. Body mass index (BMI), waist circumference and body fat declined in the histidine-supplemented group relative to the placebo group; the average fat loss in the histidine group was a robust $2.71 \mathrm{~kg}$. Markers of systemic inflammation such as serum tumour necrosis factor-alpha (TNF- $\alpha$ ) and interleukin (IL)-6, non-esterified fatty acids and oxidative stress also decreased in the histidine group. Subsequently, precisely parallel findings were reported in female rats rendered obese with a high-fat diet. ${ }^{2}$

\section{BRAIN HISTAMINE INFLUENCES APPETITE AND METABOLIC RATE}

These intriguing findings were not altogether unexpected, as earlier rodent studies had shown that supplemental histidine tends to inhibit food intake, via an impact on the hypothalamus that is mediated by the neurotransmitter histamine. ${ }^{3-6}$ Acting via $\mathrm{H} 1$ receptors in the ventromedial and paraventricular hypothalamic nuclei, histamine suppresses feeding behaviour, promotes adipocyte lipolysis via sympathetic activation and raises metabolic rate. ${ }^{38}$ These effects are analogous to those of leptin on the brain, and indeed histamine has been shown to be a key mediator of leptin signalling in the hypothalamus. ${ }^{49}$ Leptin triggers histamine release in the hypothalamus, and histamine in turn prevents the downregulation of leptin receptors which mediates leptin resistance. Crucially, whether administered intraperitoneally or intraventricularly, histidine dose dependently increases hypothalamic levels of histamine as well as hypothalamic activity of histidine decarboxylase, the enzyme which converts histidine to histamine. ${ }^{10}$ Such administration also inhibits food consumption-an effect that is blocked in animals pretreated with an irreversible inhibitor of histidine decarboxylase.

Neuronal histamine release in the hypothalamus is subject to feedback regulation by presynaptic $\mathrm{H} 3$ receptors. In rodent studies, antagonists and inverse agonists for these receptors have been shown to markedly amplify hypothalamic histamine levels, suppress feeding, decrease body weight and enhance metabolic rate. ${ }^{11-15}$ Such agents may have clinical potential for managing obesity.

The clinical relevance of these findings is further suggested by evidence that use of prescription antihistamines (H1 blockers), or of antipsychotic drugs that also inhibit $\mathrm{H} 1$, is associated with an increased risk for obesity. ${ }^{8}{ }^{16}$ Of related interest is a recent Chinese cross-sectional epidemiology correlating dietary histidine inversely with BMI, waist circumference and various markers of metabolic syndrome, in both sexes; this finding remained valid whether daily histidine intake was expressed in absolute terms, or after adjustment for protein and other dietary values. ${ }^{17}$ In a cross-sectional study enrolling female Japanese students, daily histidine intake, as well as the ratio to histidine to total dietary protein, correlated inversely with daily calorie intake after adjustment for other dietary factors ${ }^{18}$; this finding evidently is consistent with the possibility that increased brain histidine uptake can aid appetite control in humans, as it does in rodents. Moreover, a cross-sectional epidemiological study has found that 24 hours urinary excretion of histidine correlates inversely with BMI-likewise pointing to a possible role for histidine in control of energy balance. ${ }^{19}$ 


\section{BRAIN HISTAMINE REGULATES GLUCONEOGENESIS}

The amplification of brain histamine activity achievable with supplemental histidine, in addition to controlling appetite, also provokes a brain signal to the liver that decreases the expression of gluconeogenic enzymesmost notably glucose-6-phosphatase-and thereby reduces hepatic glucose output. ${ }^{20}$ A neural signal to Kupffer cells boosts their secretion of IL-6; this acts on hepatocytes to induce activating tyrosine phosphorylation of Stat3, which in turn transcriptionally represses gluconeogenic enzyme expression. ${ }^{20}$ Intracerebral insulin works in a complementary and analogous manner to restrain hepatic glucose output. ${ }^{22} 23$ These considerations suggest that supplemental histidine could aid glycaemic control in diabetics by downregulating hepatic glucose output-in addition to favourable effects on peripheral insulin sensitivity reflecting histidine's antiobesity/ anti-inflammatory actions. It is notable that, in the clinical study evaluating supplemental histidine in women with metabolic syndrome, fasting glucose fell from $5.9 \mathrm{mM}$ at baseline to $5.1 \mathrm{mM}$ after supplementation. ${ }^{1}$ And in mice rendered diabetic by streptozotocin administration (a model of type 1 diabetes), plasma glucose averaged $14.3 \mathrm{mM}$ in those who had received histidine in water at $1 \mathrm{~g} / \mathrm{L}$ for 4 weeks, as opposed to $20.6 \mathrm{mM}$ in those receiving regular water. $^{24}$ (Plasma glucose in healthy control mice was $6.3 \mathrm{mM}$.) A reduction in hepatic glucose output seems likely to be largely responsible for this effect.

\section{ANTI-INFLAMMATORY EFFECTS}

Supplemental histidine also appears to have anti-inflammatory effects on tissues that are not mediated centrally and independent of its impact on weight control, as suggested by rodent and cell-culture studies. ${ }^{24-27}$ Histidine, as well as its derivative carnosine, can exert antioxidant effects that reflect its ability to scavenge free radicals, quench singlet oxygen and chelate free transition metals. ${ }^{28-30}$ However, it should be noted that histidine availability is not rate limiting for carnosine synthesis. ${ }^{31}$ Recent prospective epidemiology has found that higher serum histidine levels predict lower risk for coronary disease in the subsequent years. ${ }^{32}$ The impact of dietary histidine on progression of atherosclerosis in rodents has not yet been studied.

\section{INTERACTION WITH BRANCHED-CHAIN AMINO ACIDS (BCAAS)}

Transport of histidine into the brain may depend not only on plasma histidine level but also onneutral amino acids-including the branched-chain amino acids (BCAAs) - that can compete for access to the neutral amino acid transporter that mediates their transport through the blood-brain barrier. ${ }^{33}$ Hence, the rate of brain histidine uptake via this transporter should be proportionate to the plasma ratio of histidine to the sum of other neutral amino acids; this sum is determined primarily by BCAA levels. This observation may be pertinent to cross-sectional studies concluding that plasma levels of BCAAs are elevated in those with type 2 diabetes, metabolic syndrome and/or obesity. ${ }^{35-40}$ Moreover, several prospective studies have found that plasma levels of BCAAs likewise correlated positively with type 2 diabetes risk. ${ }^{41-43}$ Whereas elevated BCAAs might plausibly be an effect of metabolic syndrome, ${ }^{44}$ it is also plausible that such elevations could promote weight gain and impair glycaemic control by impeding histidine's transport into the brain. Indeed, a recent Mendelian randomisation analysis concludes that elevated plasma levels of BCAA are likely to be true mediators of increased risk for type 2 diabetes. ${ }^{45}$ This phenomenon would be analogous to the well-known ability of high plasma levels of neutral amino acids to impede brain serotonin production from tryptophan. ${ }^{46}$

With respect to dietary intakes of BCAAs, a recent analysis of three large prospective cohort studies has concluded that calorie-adjusted intakes of BCAAs correlate positively with risk for onset of type 2 diabetes. ${ }^{47}$ Although this correlation continued to hold after correction for a range of covariates, it was substantially attenuated, though not eliminated, by adjustment for BMI-consistent with the possibility that elevated BCAA intake was interfering with histidine-dependent central mechanisms for regulating appetite and glycaemic control. However, a smaller Japanese prospective study reached the opposite conclusion-that higher dietary intakes of BCAAs predicted lower risk for diabetes. ${ }^{48}$ Arguably, the true dietary determinant of risk might be the ratio of histidine to BCAAs or total neutral amino acids; in this case, such a ratio, in the diet or in plasma, might better predict risk than either histidine or BCAAs per se.

\section{CAUTIONS}

Supplemental histidine may have the potential to increase histamine production by gastric enterochromaffin cells and by mast cells. Indeed, one rat study has found that stomach levels of histamine are increased as histidine intake increases beyond normal dietary levels. ${ }^{49}$ Hence, in susceptible individuals, supplemental histidine could conceivably increase risk for peptic ulcers by boosting gastric acid secretion. If this proves to be the case, supplemental histidine might be contraindicated in those prone to such ulcers or should be administered in conjunction with $\mathrm{H} 2$ receptor antagonists. The possibility that histidine supplementation could amplify symptoms in those prone to allergies by increasing histamine production in mast cells should also be considered. Moreover, it should be emphasised that there has so far been little clinical experience with histidine supplementation, and further controlled studies are needed to determine whether such supplementation can genuinely benefit human body composition and metabolic syndrome.

Contributors All authors contributed to the final manuscript. 
Funding The authors have not declared a specific grant for this research from any funding agency in the public, commercial or not-for-profit sectors.

Competing interests JJD is the author of The Salt Fix and has a website thesaltfix.com. JOK and MFM own nutraceutical companies.

Provenance and peer review Not commissioned; externally peer reviewed.

Open access This is an open access article distributed in accordance with the Creative Commons Attribution Non Commercial (CC BY-NC 4.0) license, which permits others to distribute, remix, adapt, build upon this work non-commercially, and license their derivative works on different terms, provided the original work is properly cited and the use is non-commercial. See: http://creativecommons.org/ licenses/by-nc/4.0/

Correction notice In the end matter, 'Provenance and peer review' statement has been correctly updated as 'Not commissioned; externally peer reviewed'.

(c) Article author(s) (or their employer(s) unless otherwise stated in the text of the article) 2018. All rights reserved. No commercial use is permitted unless otherwise expressly granted.

ORCID iD

James H OKeefe http://orcid.org/0000-0002-3376-5822

\section{REFERENCES}

1. Feng RN, Niu YC, Sun XW, et al. Histidine supplementation improves insulin resistance through suppressed inflammation in obese women with the metabolic syndrome: a randomised controlled trial. Diabetologia 2013;56:985-94.

2. Sun X, Feng R, Li Y, et al. Histidine supplementation alleviates inflammation in the adipose tissue of high-fat diet-induced obese rats via the NF-KB- and PPAR $\gamma$-involved pathways. Br J Nutr 2014;112:477-85.

3. Kasaoka S, Tsuboyama-Kasaoka N, Kawahara Y, et al. Histidine supplementation suppresses food intake and fat accumulation in rats. Nutrition 2004;20(11-12):991-6.

4. Yoshimatsu H, Itateyama E, Kondou S, et al. Hypothalamic neuronal histamine as a target of leptin in feeding behavior. Diabetes 1999;48:2286-91.

5. Jørgensen EA, Vogelsang TW, Knigge U, et al. Increased susceptibility to diet-induced obesity in histamine-deficient mice. Neuroendocrinology 2006;83(5-6):289-94.

6. Gotoh K, Masaki T, Chiba S, et al. Hypothalamic neuronal histamine signaling in the estrogen deficiency-induced obesity. J Neurochem 2009;110:1796-805.

7. Yoshimatsu H, Tsuda K, Niijima A, et al. Histidine induces lipolysis through sympathetic nerve in white adipose tissue. Eur J Clin Invest 2002;32:236-41.

8. He M, Deng C, Huang XF. The role of hypothalamic $\mathrm{H} 1$ receptor antagonism in antipsychotic-induced weight gain. CNS Drugs 2013;27:423-34.

9. Morimoto T, Yamamoto Y, Yamatodani A. Leptin facilitates histamine release from the hypothalamus in rats. Brain Res 2000;868:367-9.

10. Yoshimatsu H, Chiba S, Tajima D, et al. Histidine suppresses food intake through its conversion into neuronal histamine. Exp Biol Med 2002;227:63-8.

11. Sakata T, Yoshimatsu H, Kurokawa M. Hypothalamic neuronal histamine: implications of its homeostatic control of energy metabolism. Nutrition 1997;13:403-11.

12. Jethwa $\mathrm{PH}$, Barrett $\mathrm{P}$, Turnbull $\mathrm{Y}$, et al. The role of histamine 3 receptors in the control of food intake in a seasonal model of obesity: the Siberian hamster. Behav Pharmacol 2009;20:155-65.

13. Deng C, Weston-Green K, Huang XF. The role of histaminergic $\mathrm{H} 1$ and $\mathrm{H} 3$ receptors in food intake: a mechanism for atypical antipsychotic-induced weight gain? Prog Neuropsychopharmacol Biol Psychiatry 2010;34:1-4.

14. Clapp RH, Luckman SM. Proxyfan acts as a neutral antagonist of histamine $\mathrm{H} 3$ receptors in the feeding-related hypothalamic ventromedial nucleus. Br J Pharmacol 2012;167:1099-110.

15. Ishizuka T, Hatano K, Murotani T, et al. Comparison of the effect of an $\mathrm{H}(3)$-inverse agonist on energy intake and hypothalamic histamine release in normal mice and leptin resistant mice with high fat dietinduced obesity. Behav Brain Res 2008;188:250-4.

16. Ratliff JC, Barber JA, Palmese LB, et al. Association of prescription $\mathrm{H} 1$ antihistamine use with obesity: results from the National Health and Nutrition Examination Survey. Obesity 2010;18:2398-400.
17. Li YC, Li CL, Qi JY, et al. Relationships of dietary histidine and obesity in northern chinese adults, an internet-based cross-sectional study. Nutrients 2016;8.

18. Okubo H, Sasaki S. Histidine intake may negatively correlate with energy intake in human: a cross-sectional study in Japanese female students aged 18 years. J Nutr Sci Vitaminol 2005;51:329-34.

19. Yamori Y. Worldwide epidemic of obesity: hope for Japanese diets. Clin Exp Pharmacol Physiol 2004;31(Suppl 2):S2-S4.

20. Kimura K, Nakamura Y, Inaba Y, et al. Histidine augments the suppression of hepatic glucose production by central insulin action. Diabetes 2013;62:2266-77.

21. Inoue $\mathrm{H}$, Ogawa W, Ozaki M, et al. Role of STAT-3 in regulation of hepatic gluconeogenic genes and carbohydrate metabolism in vivo. Nat Med 2004;10:168-74.

22. Inoue $\mathrm{H}$, Ogawa W, Asakawa A, et al. Role of hepatic STAT3 in brain-insulin action on hepatic glucose production. Cell Metab 2006;3:267-75

23. Heni M, Wagner R, Kullmann S, et al. Hypothalamic and striatal insulin action suppresses endogenous glucose production and may stimulate glucose uptake during hyperinsulinemia in lean but not in overweight men. Diabetes 2017;66:1797-806.

24. Lee YT, Hsu CC, Lin MH, et al. Histidine and carnosine delay diabetic deterioration in mice and protect human low density lipoprotein against oxidation and glycation. Eur J Pharmacol 2005;513:145-50.

25. Yan SL, Wu ST, Yin MC, et al. Protective effects from carnosine and histidine on acetaminophen-induced liver injury. $J$ Food Sci 2009;74:H259-H265.

26. Andou A, Hisamatsu T, Okamoto S, et al. Dietary histidine ameliorates murine colitis by inhibition of proinflammatory cytokine production from macrophages. Gastroenterology 2009;136:564-74.

27. Hasegawa S, Ichiyama T, Sonaka I, et al. Cysteine, histidine and glycine exhibit anti-inflammatory effects in human coronary arterial endothelial cells. Clin Exp Immunol 2012;167:269-74.

28. Velez S, Nair NG, Reddy VP. Transition metal ion binding studies of carnosine and histidine: biologically relevant antioxidants. Colloids Surf B Biointerfaces 2008;66:291-4.

29. Lee JW, Miyawaki H, Bobst EV, et al. Improved functional recovery of ischemic rat hearts due to singlet oxygen scavengers histidine and carnosine. J Mol Cell Cardiol 1999;31:113-21.

30. Decker EA, Ivanov V, Zhu BZ, et al. Inhibition of low-density lipoprotein oxidation by carnosine histidine. J Agric Food Chem 2001;49:511-6

31. Blancquaert L, Everaert I, Missinne M, et al. Effects of Histidine and $\beta$-alanine Supplementation on Human Muscle Carnosine Storage. Med Sci Sports Exerc 2017;49:602-9.

32. Yu B, Li AH, Muzny D, et al. Association of rare loss-of-function alleles in HAL, serum histidine: levels and incident coronary heart disease. Circ Cardiovasc Genet 2015;8:351-5.

33. Oldendorf WH, Szabo J. Amino acid assignment to one of three blood-brain barrier amino acid carriers. Am J Physiol 1976;230:94-8.

34. Oldendorf WH, Crane PD, Braun LD, et al. pH dependence of histidine affinity for blood-brain barrier carrier transport systems for neutral and cationic amino acids. J Neurochem 1988;50:857-61.

35. Xu F, Tavintharan S, Sum CF, et al. Metabolic signature shift in type 2 diabetes mellitus revealed by mass spectrometry-based metabolomics. J Clin Endocrinol Metab 2013;98:E1060-E1065.

36. Newgard CB, An J, Bain JR, et al. A branched-chain amino acid-related metabolic signature that differentiates obese and lean humans and contributes to insulin resistance. Cell Metab 2009;9:311-26.

37. McCormack SE, Shaham O, McCarthy MA, et al. Circulating branched-chain amino acid concentrations are associated with obesity and future insulin resistance in children and adolescents. Pediatr Obes 2013;8:52-61.

38. Tai ES, Tan ML, Stevens RD, et al. Insulin resistance is associated with a metabolic profile of altered protein metabolism in Chinese and Asian-Indian men. Diabetologia 2010;53:757-67.

39. Hu W, Sun L, Gong Y, et al. Relationship between branched-chain amino acids, metabolic syndrome, and cardiovascular risk profile in a Chinese population: a cross-sectional study. Int J Endocrinol 2016;2016:1-10.

40. Lee CC, Watkins SM, Lorenzo C, et al. Branched-chain amino acids and insulin metabolism: the Insulin Resistance Atherosclerosis Study (IRAS). Diabetes Care 2016;39:582-8.

41. Wang TJ, Larson MG, Vasan RS, et al. Metabolite profiles and the risk of developing diabetes. Nat Med 2011;17:448-53.

42. Lu Y, Wang Y, Ong CN, et al. Metabolic signatures and risk of type 2 diabetes in a Chinese population: an untargeted metabolomics study using both LC-MS and GC-MS. Diabetologia 2016;59:2349-59. 
43. Chen T, Ni Y, Ma X, et al. Branched-chain and aromatic amino acid profiles and diabetes risk in Chinese populations. Sci Rep 2016;6:20594.

44. Yoon MS. The emerging role of branched-chain amino acids in insulin resistance and metabolism. Nutrients 2016;8:405.

45. Lotta LA, Scott RA, Sharp SJ, et al. Genetic predisposition to an impaired metabolism of the branched-chain amino acids and risk of type 2 diabetes: a mendelian randomisation analysis. PLoS Med 2016;13:e1002179.

46. Fernstrom JD, Wurtman RJ. Brain serotonin content: physiological regulation by plasma neutral amino acids. Science 1972;178:414-6.
47. Zheng Y, Li Y, Qi Q, et al. Cumulative consumption of branchedchain amino acids and incidence of type 2 diabetes. Int $J$ Epidemiol 2016;45:1482-92.

48. Nagata C, Nakamura K, Wada K, et al. Branched-chain amino acid intake and the risk of diabetes in a Japanese community: the Takayama study. Am J Epidemiol 2013;178:1226-32.

49. Lee NS, Fitzpatrick D, Meier E, et al. Influence of dietary histidine on tissue histamine concentration, histidine decarboxylase and histamine methyltransferase activity in the rat. Agents Actions 1981;11:307-11. 